Lowest Attainable Temperatures". The Huxley Lecture is to be given on March 16 at the University, Edmund Street, by Sir Albert Seward on "Aspects of Evolution in the Plant World".

\section{Vocational Rehabilitation of the Physically Disabled}

A STUDY of the vocational rehabilitation of the physically disabled has been prepared for the Advisory Committee on Education by Lloyd E. Blanch (U.S. Government Printing Office, Staff Study No. 9). The study reviews the development, status and problems of the rehabilitation service inaugurated in July 1920 by the Federal Government, under which up to June $30,1937,98,690$ persons had been rehabilitated. In the year ended June 30, 1937, vocational rehabilitation was completed for 8,691 men and 2,400 women, about 60 per cent of whom received some training. Maintenance was provided or secured for 948 while they were undergoing rehabilitation. Of those rehabilitated, 64 per cent were less than thirty-one years of age and only 8 per cent were more than fifty. Most of those rehabilitated (61 per cent) were without dependants, but 26 per cent had two or more dependants. Orthopædic disabilities handicapped 75 per cent of those rehabilitated. The study suggests that 150,000 persons each year acquire permanent disabilities sufficiently serious to prevent them from returning to work without assistance. About 50,000 of these can be employed normally after rehabilitation; 75,000 can be employed only in sheltered workshop conditions, while the remaining 25,000 can only be employed, if at all, in their homes. Accordingly the present programme only rehabilitates about 20 per cent of the physically disabled who need such assistance. The study concludes that a permanent Federal programme is required and insists on the importance of Federal administration and of the co-ordination of Federal services which affect vocational rehabilitation. Reference is also made to special services for the blind and to the need for an extended programme, including the provision of living expenses during rehabilitation.

\section{The New Deal in the United States}

IN Fact of October 1938, under the title "Roosevelt and his New Deal", Stephen K. Bailey gives a concise account of the achievements of the New Deal up to the end of September, which indicates not merely the problems which faced Roosevelt but also the background of social and economic conflict against which they have to be assessed. In successive chapters, the attempts made to meet the needs of the farmer, under the Agricultural Adjustment Administration and the Farm Credit Administration, etc., the industrialist, under the National Industrial Recovery Act and the Public Works Administration, as well as the needs of labour and the unemployment situation by the Federal Relief Administration, are sur. veyed. The complexity of the situation is clearly indicated as well as the way in which the conflict between big business interests and labour has been intensified, the difficulties which the Federation has to overcome in the direction of social reform, the establishment of a really sound banking system, and the problem of the Supreme Court. Mr. Bailey hazards no guess as to the outcome of the present situation: the successes and failures of the New Deal are impartially indicated as well as some of the reasons for the vagaries of American foreign policy; but his account, whether or not it is used as an introduction to further study, should at least contribute to the sympathetic understanding of the American situation, although the rather sombre picture he gives of the relation between employers and employees and of the attitude of the former to social reform does not encourage optimism.

\section{Selection of Sizes of Timber Beams}

THE determination of the suitable breadth and depth of a timber beam to carry a given load involves consideration of strength, of stiffness, and of the capacity of the material to withstand the horizontal shear forces induced in it by the transverse loading. The calculations which these considerations necessitate can, however, be entirely eliminated by making use of a set of three charts recently published under the title "Charts for the Design of Timber Beams". These charts have been prepared by V. D. Limaye, officer-in-charge of the Timber Testing Station, Forest Research Institute, Dehra Dun, United Provinces. The first of them is designed to ensure that a beam of adequate strength is chosen. In it two nomographs are provided which, from the given load per square foot, span, and spacing, ascertain the total load carried by the beam. Then, by the drawing of four horizontal and vertical lines terminated by suitably placed diagonal lines which are embodied in the chart, the breadth and depth of a sufficiently strong beam are obtained. In most cases in which timber beams are used, it is necessary to restrict the deflection under load to certain specified limits, and stiffness has therefore to be arranged. This is done by means of the second chart, which enables the correct amount of adjustment to be made in the sizes already determined so that the required degree of stiffness is assured, and the process involves only the drawing of another set of horizontal and vertical lines. In the third chart a third series of horizontal and vertical lines leading to a final nomograph either confirms the horizontal shear strength as adequate or shows the correction required so that, in the end, the section evolved is suitable for its purpose from all points of view.

\section{Magneto or Coil Ignition for Motor-Cars}

F. R. Haigh has recently compared the relative advantages of magneto and coil ignition used for generating the explosions which occur in motor-car engines (Students' Quart. J. Inst. Elec. Eng., Dec.). Coil ignition was prominent on the early types of petrol engines, but magnetos appeared on the market and for a number of years prior to 1914 a Bosch magneto was regarded as the acme of perfection. About ten years ago coil ignition systems came to the front. 'The magneto is of great importance in aero work and is popular on racing-cars, but in motor-vehicles it has been almost entirely replaced by coil ignition. Modern coil ignition systems are 